July-August 1995

Volume 100, Number 4

\title{
Journal of Research of the
}

Special Issue

Gaseous Electronics Conference

RF Reference Cell

National

Institute of

Standards and

Technology 
$T$ he National Institute of Standards and Technology was established in 1988 by Congress to "assist industry in the development of technology ... needed to improve product quality, to modernize manufacturing processes, to ensure product reliability . . . and to facilitate rapid commercialization . . . of products based on new scientific discoveries."

NIST, originally founded as the National Bureau of Standards in 1901, works to strengthen U.S. industry's competitiveness; advance science and engineering; and improve public health, safety, and the environment. One of the agency's basic functions is to develop, maintain, and retain custody of the national standards of measurement, and provide the means and methods for comparing standards used in science, engineering, manufacturing, commerce, industry, and education with the standards adopted or recognized by the Federal Government.

As an agency of the U.S. Commerce Department's Technology Administration, NIST conducts basic and applied research in the physical sciences and engineering, and develops measurement techniques, test methods, standards, and related services. The Institute does generic and precompetitive work on new and advanced technologies. NIST's research facilities are located at Gaithersburg, MD 20899, and at Boulder, CO 80303. Major technical operating units and their principal activities are listed below. For more information contact the Public Inquiries Desk, 301-975-3058.

\section{Office of the Director}

- Advanced Technology Program

- Quality Programs

- International and Academic Affairs

\section{Technology Services}

- Manufacturing Extension Partnership

- Standards Services

- Technology Commercialization

- Measurement Services

- Technology Evaluation and Assessment

- Information Services

\section{Materials Science and Engineering} Laboratory

- Intelligent Processing of Materials

- Ceramics

- Materials Reliability ${ }^{1}$

- Polymers

- Metallurgy

- Reactor Radiation

\section{Chemical Science and Technology}

\section{Laboratory}

- Biotechnology

- Chemical Kinetics and Thermodynamics

- Analytical Chemical Research

- Process Measurements

- Surface and Microanalysis Science

- Thermophysics ${ }^{2}$

\section{Physics Laboratory}

- Electron and Optical Physics

- Atomic Physics

- Molecular Physics

- Radiometric Physics

- Quantum Metrology

- Ionizing Radiation

- Time and Frequency ${ }^{1}$

- Quantum Physics ${ }^{1}$
Manufacturing Engineering Laboratory

- Precision Engineering

- Automated Production Technology

- Intelligent Systems

- Manufacturing Systems Integration

- Fabrication Technology

\section{Electronics and Electrical Engineering} Laboratory

- Microelectronics

- Law Enforcement Standards

- Electricity

- Semiconductor Electronics

- Electromagnetic Fields ${ }^{1}$

- Electromagnetic Technology ${ }^{1}$

- Optoelectronics ${ }^{1}$

\section{Building and Fire Research Laboratory}

- Structures

- Building Materials

- Building Environment

- Fire Safety

- Fire Science

\section{Computer Systems Laboratory}

- Office of Enterprise Integration

- Information Systems Engineering

- Systems and Software Technology

- Computer Security

- Systems and Network Architecture

- Advanced Systems

\section{Computing and Applied Mathematics \\ Laboratory}

- Applied and Computational Mathematics ${ }^{2}$

- Statistical Engineering ${ }^{2}$

- Scientific Computing Environments ${ }^{2}$

- Computer Services

- Computer Systems and Communications ${ }^{2}$

- Information Systems

\footnotetext{
${ }^{1}$ At Boulder, CO 80303.

${ }^{2}$ Some elements at Boulder, CO 80303.
} 


\section{Journal of Research of the National Institute of Standards and Technology}

\section{Board of Editors}

Barry N. Taylor

Chief Editor

Jean W. Gallagher, Technology Services

Richard J. Van Brunt, Electronics and Electrical Engineering Laboratory

Theodore V. Vorburger, Manufacturing Engineering Laboratory

John R. Moody, Chemical Science and Technology Laboratory

Ronald Collé, Physics Laboratory

Kenneth L. Jewett, Materials Science and Engineering Laboratory

Piotr A. Domanski, Building and Fire Research Laboratory

Alan H. Goldfine, Computer Systems Laboratory

Daniel W. Lozier, Computing and Applied Mathematics Laboratory

Matt Young, Boulder Laboratories

Chris E. Kuyatt, Washington Editorial Review Board

\section{Donald R. Harris}

Managing Editor

Julian M. Ives

Technical Production Editor

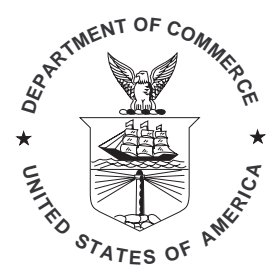

U.S. Department of Commerce-Ronald H. Brown, Secretary

Technology Administration-Mary L. Good, Under Secretary for Technology

National Institute of Standards and Technology_Arati Prabhakar, Director 
The Journal of Research of the National Institute of Standards and Technology features advances in measurement methodology and analyses consistent with the NIST responsibility as the nation's measurement science laboratory. It includes reports on instrumentation for making accurate and precise measurements in fields of physical science and engineering, as well as the mathematical models of phenomena which enable the predictive determination of information in regions where measurements may be absent. Papers on critical data, calibration techniques, quality assurance programs, and well-characterized reference materials reflect NIST programs in these areas. Special issues of the Journal are devoted to invited papers in a particular field of measurement science. Occasional survey articles and conference reports appear on topics related to the Institute's technical and scientific programs. 


\section{The Gaseous Electronics Conference Radio-Frequency Reference Cell}

\section{Preface}

One of the most important commercial applications of low-temperature, radio-frequency (rf) glow discharges is the fabrication of microelectronic circuitry. However, many plasma-based production processes suffer from reliability problems. A process may work well for some time and then fail mysteriously, or a process may yield certain results in one plasma reactor, and completely different results in another. These types of uncertainties in process and reactor performance cause decreased manufacturing efficiency, increased costs, and limit the development of increasingly complex semiconductor devices.

The unpredictability of semiconductor fabrication processes has been attributed to subtle differences in reactor conditions that could not easily be detected, such as feed gas impurities, surface conditioning, surface charging, and minor variations in electrical circuits. However, progress in isolating the effects of these conditions was slowed by the fact that the plasma reactors used by many researchers were so vastly different in design from one another, that differences in experimental data due to reactor conditions could not be separated from the effects of different reactor geometries.

An attempt to formally address this problem at the 1988 Gaseous Electronics Conference (GEC) resulted in the design of the GEC RF Reference Cell: a parallel plate, capacitively-coupled, rf plasma reactor that, in principle, is suitable for studies of basic discharge phenomena, investigation of industrial-type plasmas, and theoretical modeling. The use of several of these chambers to perform similar experiments in different laboratories, with subsequent comparison of results, was proposed to isolate the effects of reactor geometry from other experimental variables. Over the years, the number of GEC Cells has increased from 6 to 25, and they are now found in 19 different laboratories throughout the United States and Europe. Work performed on GEC Cells has resulted in the publication of over 75 articles and reports, and has been presented at numerous conferences.

At the 1993 Gaseous Electronics Conference, it was determined that a sufficient amount of research had been performed on GEC Cells that a review of the available data would be useful, and so it was decided that a Special Issue of the Journal of Research of the National Institute of Standards and Technology would be dedicated to work performed on GEC RF Reference Cells. Submission of articles to this Special Issue corresponded to the hosting of the 1994 Gaseous Electronics Conference by NIST. The issue before you is the result of that decision. This issue contains 12 articles that review nearly all of the experiments and theoretical modeling efforts that have been performed over the last 5 years using GEC Cells. While the emphasis of these articles is on the comparison of data obtained on different GEC Cells, together they serve as a "users' guide" to the operation and performance of the GEC Cell. Hopefully, this makes this issue useful to both novices and experts in the plasma processing community.

All of the articles in this issue have been reviewed, and I am grateful to the many scientists at NIST and elsewhere who served as referees. I also wish to thank Julian Ives for his invaluable assistance in the production of this Special Issue. 


\section{ontents}

\section{The Gaseous Electronics Conference Radio-Frequency Reference Cell}

Preface

\section{Articles}

The Gaseous Electronics Conference RF Reference CellAn Introduction

Current and Voltage Measurements in the Gaseous Electronics Conference RF Reference Cell

Optical Emission Spectroscopy on the Gaseous Electronics Conference RF Reference Cell

Optical Diagnostics in the Gaseous Electronics Conference RF Reference Cell

Studies of Ion Kinetic-Energy Distributions in the Gaseous Electronics Conference RF Reference Cell

Microwave Diagnostic Results from the Gaseous Electronics Conference RF Reference Cell

Langmuir Probe Measurements in the Gaseous Electronics Conference RF Reference Cell

An Inductively Coupled Plasma Source for the Gaseous Electronics Conference RF Reference Cell

Reactive Ion Etching in the Gaseous Electronics Conference RF Reference Cell

Dusty Plasma Studies in the Gaseous Electronics Conference RF Reference Cell

One-Dimensional Modeling Studies of the Gaseous Electronics Conference RF Reference Cell

Two-Dimensional Self-Consistent Radio Frequency Plasma Simulations Relevant to the Gaseous Electronics Conference RF Reference Cell
J. K. Olthoff and

K. E. Greenberg

Mark A. Sobolewski

J. R. Roberts

G. A. Hebner and

Kenneth E. Greenberg

J. K. Olthoff, R. J. Van Brunt, and S. B. Radovanov

Paul A. Miller, Gregory A.

Hebner, Kenneth E. Greenberg,

Paul D. Pochan, and

Ben P. Aragon

\section{L. Brake, J. T. P. Pender, \\ M. J. Buie, A. Ricci, J. Soniker, P. D. Pochan, and P. A. Miller}

H. M. Anderson and and Demetre J. Economou

\section{1}

\section{3}

\section{3}




\section{News Briefs}

\section{GENERAL DEVELOPMENTS}

New Web Site Serves as Guide to NII

Photovoltaic Hot Water System Exceeds Expectations

Stress Measurements Assess Railroad Wheel Safety

August Conference Focuses on Diamond Applications

Accurate Prices Goal of New NCWM Procedure

USDA Adopts Updated Versions of Two NIST Handbooks

Energy-Related Inventions Program Recommendations

NIST Helps Company with Measurement of Pulse Energy for Inkjet Print-Heads

Bioelectrical Impedance Analyzers Studied

Partial Discharge Measurement Laboratory Established

NIST Facilitates International Workshop on Ultra-Shallow Profiles in Semiconductors

NIST Testing Machining Centers for Industry

NIST and Private Company Collaborate in Presenting the Practical Application of

Scanned Probe Microscopy

NIST'S Participation in the Newly Launched Apparel Research Network Program

X-Ray Spectrometry in Electron Beam Instruments

New Publication Focuses on Analytical Methods for Cancer Chemopreventive Agents

Workshop on the "Treatment of Gaseous Emissions via Plasma Technology"

Hosted by NIST

NIST Parallel Applications Development Environment (PADE) Released

Nanodetector Produces First Images

CRADA Signed with Private Company to Share Parallel Computing Software

NIST and the Council on Ionizing Radiation Measurements and Standards Host

Workshop on Radiation Protection

Photonic Films

Workshop on Materials Property Measurements

X-Ray Diffraction Imaging of ZnSe Substrates for Blue-Green LEDs

Thermal Barrier Coatings Workshop

NIST Work Featured at Automotive Conference

Thermal Behavior of Polymer Ultrathin Films

Thermal Diffusivity Measurements in Multilayer Thermal Barrier Coatings

NSF Renews Support for the Center for High Resolution Neutron Scattering

NIST Develops New Method for Measuring Refrigerant Flammability

NIST Participates in Development of Remote Database Access Standard

Secretary of Commerce Approves Federal Information Processing Standard (FIPS) for

Document Application Profile

New Publication Looks at Object-Oriented Technology

Information Security Training Attracts Large Federal Audience

NVCASE Public Workshop Held

Calibration Accreditation

Cryptographic Module Validation 
Patent Issued on the Application of Arrays of Miniature Hotplates to Materials Processing

Latest Gage Block Calibration System at NIST

NIST Asserts New Approach to Unifying Rockwell Hardness Standards

First Technical Meeting of Computer-Aided Manufacturing Forum Held

International Comparison of Humidity Standards at NIST

Synthesis and In Situ Characterization of Superparamagnetic Nanocomposites from

Vapor Phase Condensation in a Flame

Computational Thermochemistry of $\mathrm{Si}_{x} \mathrm{H}_{y} \mathrm{O}_{z}$ Reactions

Role of Radiocarbon Measurement Technology in Meeting Urban Air Quality Standards

Eighth Annual Workshop on Secondary Ion Mass Spectrometry

Workshop on Infrared Microspectroscopy With Synchrotron Radiation Sources

Ocean Radiometry Workshop at NIST

CRADA Investigates Radiation Engineering for Environmental Cleanup

NIST Assists Industry in Thermoplastics Engineering Design

Method Developed to Measure Material Density at Surfaces

Micromagnetic Modeling Workshop

NIST Researchers Receive Patent for a Welding Control System

NIST Hosts Joint Meeting with NSF Center for Science and Technology of Advanced

Cement-Based Materials

NIST Models Radon Transport in Large Multizone Buildings

Fault Detection and Diagnosis Using Artificial Neural Networks

Proceedings of Text Retrieval Conference Published

New Publication Gives Blueprint for Electronic Access to Historical Information

Report Details Benefits of Electronic Workshop

Commerce, Energy Join Forces to Aid Manufacturers

First Full-Scale Fire Tests for High Ceilings Done

Distribution Amplifiers Yield Low Noise, High Isolation

STANDARD REFERENCE MATERIALS

SRM 2391-PCR-Based DNA Profiling Standard

Eight Thousand Series RMs for Fine Gold, Fine Silver, and Gold Bullion from the Royal

Canadian Mint (RCM)

SRM 1632b, 1635 Trace Elements in Coal

SRM 656-Silicon Nitride Powders for Quantitative Analysis by Powder Diffraction 